\title{
The relationship between plasmapause, solar wind and geomagnetic activity between 2007 and 2011
}

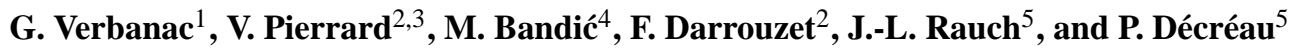 \\ ${ }^{1}$ Department of Geophysics, University of Zagreb, Zagreb, Croatia \\ ${ }^{2}$ Belgian Institute for Space Aeronomy (Space Physics and STCE), 3 Av. Circulaire, 1180 Brussels, Belgium \\ ${ }^{3}$ Université Catholique de Louvain, TECLIM, Earth and Life Institute, Place Louis Pasteur 3 bte L4.03.08, \\ 1348 Louvain-La-Neuve, Belgium \\ ${ }^{4}$ Preziosastr. 15a, 81927 München, Germany \\ ${ }^{5}$ Laboratoire de Physique et Chimie de l'Environnement et de l'Espace (LPC2E), Orléans, France
}

Correspondence to: G. Verbanac (giuli1.verbanac@gmail.com)

Received: 11 May 2015 - Revised: 23 July 2015 - Accepted: 4 September 2015 - Published: 16 October 2015

\begin{abstract}
Taking advantage of the Cluster satellite mission and especially the observations made by the instrument WHISPER to deduce the electron number density along the orbit of the satellites, we studied the relationships between the plasmapause positions $\left(L_{\mathrm{PP}}\right)$ and the following $L_{\mathrm{PP}}$ indicators: (a) solar wind coupling functions $B_{z}$ ( $Z$ component of the interplanetary magnetic field vector, $\boldsymbol{B}$, in GSM system), $\mathrm{BV}$ (related to the interplanetary electric field; $B$ is the magnitude of the interplanetary magnetic field vector, $V$ is solar wind velocity), and $\mathrm{d} \Phi_{\mathrm{mp}} / \mathrm{d} t$ (which combines different physical processes responsible for the magnetospheric activity) and (b) geomagnetic indices Dst, Ap and AE. The analysis is performed separately for three magnetic local time (MLT) sectors (Sector1 - night sector (01:00-07:00 MLT); Sector2 - day sector (07:00-16:00 MLT); Sector3 - evening sector (16:00-01:00 MLT)) and for all MLTs taken together. All $L_{\mathrm{PP}}$ indicators suggest the faster plasmapause response in the postmidnight sector. Delays in the plasmapause responses (hereafter time lags) are approximately $2-27 \mathrm{~h}$, always increasing from Sector1 to Sector3. The obtained fits clearly resolve the MLT structures. The variability in the plasmapause is the largest for low values of $L_{\mathrm{PP}}$ indicators, especially in Sector2. At low activity levels, $L_{\mathrm{PP}}$ exhibits the largest values on the dayside (in Sector2) and the smallest on the postmidnight side (Sector1). Displacements towards larger values on the evening side (Sector3) and towards lower values on the dayside (Sector2) are identified for enhanced magnetic activity. Our results contribute to constraining the
\end{abstract}

physical mechanisms involved in the plasmapause formation and to further study the still not well understood related issues.

Keywords. History of geophysics (solar-planetary relationships) - interplanetary physics (interplanetary magnetic fields; instruments and techniques)

\section{Introduction}

The plasmasphere is the continuation of the ionosphere into the magnetosphere and represents the region of cold and relatively dense plasma in the inner magnetosphere (Lemaire and Gringauz, 1998; Darrouzet et al., 2009a). The base of the plasmasphere is defined as the transition from atomic oxygen to atomic hydrogen and occurs at altitudes between 500 and $2000 \mathrm{~km}$ depending on the geophysical conditions (Prölss, 2004a). The outer boundary of the plasmasphere, called the plasmapause, represents the cutoff in the plasma density, the location of which depends on the level of the geomagnetic disturbances. In the equatorial plane the plasmapause is typically found near 5-7 $R_{\mathrm{E}}$ (e.g., Chappell et al., 1970a; Carpenter and Lemaire, 2004; Pedatella and Larson, 2010).

The plasmapause position, $L_{\mathrm{PP}}$, is determined by the large-scale convection electric field which is superimposed on the corotation electric field. The convection electric field is the result of the interaction of the solar wind with the 
geomagnetic field. The corotation electric field is produced in the $\mathrm{E}$ region of the ionosphere and is conveyed into the plasmasphere along the magnetic field lines. During increasing magnetic activity, the stronger convection electric field pushes the plasmapause closer to the Earth (down to $2 R_{\mathrm{E}}$ Goldstein et al., 2004), peeling off the outer layers of the plasmasphere. On the other hand, during decreasing activity the plasmapause moves outward, and a slow refilling process from the dayside $\mathrm{F}$ region ionosphere begins. These characteristics are in agreement with the observations of Cluster (e.g., Darrouzet and De Keyser, 2013) and IMAGE satellite data (e.g., Goldstein et al., 2004).

The $L_{\mathrm{PP}}$ and its dependence on the geomagnetic activity have been studied both theoretically and empirically. The $L_{\mathrm{PP}}$ has been directly related to the time variations in the convection electric field.

Two theoretical approaches have been used to describe the dynamics of the $L_{\mathrm{PP}}$ : (i) the last closed streamline of the equatorial plasma related to the last closed equipotential of the electric field (Brice, 1967; Lemaire and Pierrard, 2008) and (ii) the interchange instability mechanism appearing in the postmidnight sector during geomagnetic storms and substorms (Pierrard and Lemaire, 2004; Lemaire and Pierrard, 2008).

Empirical $L_{\mathrm{PP}}$ has been estimated by examining groundbased whistler observations, in situ satellite density measurements (e.g., ISEE, CRRES), field-aligned current signature observations (CHAMP) and geomagnetic indices (Chappell et al., 1970b; Horwitz et al., 1986; Carpenter and Anderson, 1992; Gallagher et al., 2000; Moldwin et al., 2002; O’Brien and Moldwin, 2003; Heilig and Lühr, 2013).

The often cited model of Carpenter and Anderson (1992) gives the $L_{\mathrm{PP}}$ as a function of the maximum of the geomagnetic Kp index observed in the previous $24 \mathrm{~h}$. Moldwin et al. (2002) expressed the $L_{\mathrm{PP}}$ as a function of the maximum $\mathrm{Kp}$ index in the previous $12 \mathrm{~h}$. O'Brien and Moldwin (2003) extended that investigation by using Kp, Dst and AE geomagnetic indices taking the hours relative to the plasmapause crossing: 36 for Kp, 24 for Dst and 36 for AE. The new feature in their model is the $L_{\mathrm{PP}}$ magnetic local time (MLT) dependence.

They obtained a little difference in the quality of the plasmapause models for different indices and a lack of local time dependences in the Dst model. A new empirical model of the $L_{\mathrm{PP}}$ based on field-aligned currents measured by the CHAMP (CHAllenging Minisatellite Payload) satellite was introduced by Heilig and Lühr (2013). All these studies found that the plasmapause is more earthward during geomagnetically active periods with the plasmapause bulge displaced toward dusk.

In the three-dimensional dynamic model of the plasmasphere (Pierrard and Stegen, 2008) that has been recently coupled to the ionosphere (Pierrard and Voiculescu, 2011), the plasmapause depends on the MLT and on the Kp index observed during the last $24 \mathrm{~h}$. During substorm and storm events, the geomagnetic activity increases and enhances the convection electric field, mainly in the postmidnight MLT sector. This leads to an inward motion of the plasmapause closer to the Earth in this sector and then later in other MLT sectors due to the corotation of the plasmapause with the Earth. Using a E5D convection electric field (Mcllwain, 1986), the equatorial $L_{\mathrm{PP}}$ is calculated in all MLT sectors and is provided on the European space weather portal (www.spaceweather.eu). Using the same mechanism but stronger convection electric fields, the plasmapause position is found to be closer to the Earth (Pierrard et al., 2008).

Larsen et al. (2007) correlated the average plasmapause radial positions observed by the EUV (Extreme Ultraviolet Imager) instrument on IMAGE with the solar wind parameters: $B_{z}$ ( $Z$ component of the interplanetary magnetic field, IMF, vector $\boldsymbol{B}$ in the geocentric solar magnetospheric system, GSM), the IMF clock angle, and the polar cap potential drop $\phi$. The $L_{\mathrm{PP}}$ is found to be most tightly correlated with $B_{z}$. The time lags in the plasmapause response to $B_{z}$ and IMF clock angle were found to be $180 \mathrm{~min}$, and $240 \mathrm{~min}$ with respect to $\phi$.

In the present study, we investigate the $L_{\mathrm{PP}}$ determined by the WHISPER (Waves of HIgh frequency and Sounder for Probing of Electron density by Relaxation) instrument (Décréau et al., 1997) on board Cluster as a function of various $L_{\mathrm{PP}}$ indicators:

a. solar wind coupling functions $B_{z}, \mathrm{BV}$ related to the interplanetary electric field ( $B$ is the magnitude of the IMF vector $\boldsymbol{B}, V$ is solar wind velocity), and novel function $\mathrm{d} \Phi_{\mathrm{mp}} / \mathrm{d} t$ introduced by Newell et al. (2007), which combines different physical processes responsible for the magnetospheric activity and is explained in detail in Sect. 2;

b. geomagnetic indices Dst, Ap and AE.

We carry out our investigation by applying the crosscorrelation analysis. The study is performed separately for three MLT sectors (Sector1 - night sector (01:0007:00 MLT); Sector2 - day sector (07:00-16:00 MLT); Sector3 - evening sector (16:00-01:00 MLT)) and for all MLT taken together. Our approach is based on the $L_{\mathrm{PP}}$ indicator values at the highest-correlation time lag, instead of the interval maxima as in previous studies listed above.

The paper is organized as follows. After this introduction, Sect. 2 describes the data and method of analysis. Section 3 contains the characteristics of the analyzed samples. In Sect. 4 we present the results of the cross-correlations between $L_{\mathrm{PP}}$ and various $L_{\mathrm{PP}}$ indicators. Discussions of the obtained results and conclusions are given in the last section. 


\section{Data sets and method}

Our study is based on the following data sets:

- 1-hour averages of geomagnetic indices Dst and AE;

- 3-hour averages of geomagnetic index Ap;

- 1-hour averages of the solar wind parameters (velocity $V$, IMF magnitude $B$ and components $B_{x}, B_{y}, B_{z}$ in GSM coordinate frame of the IMF vector $\boldsymbol{B}$ );

- time-frequency electric field spectrograms during the plasmasphere crossing.

The planetary geomagnetic activity index, Ap, the stormtime disturbance index, Dst, and the auroral electrojet index, AE, are downloaded from ftp://ftp.ngdc.noaa.gov/STP/ GEOMAGNETIC_DATA/INDICES/KP_AP and http://wdc. kugi.kyoto-u.ac.jp/dstae/index.html. For more detailed information about the indices, we refer to Prölss (2004b) and Verbanac et al. (2010, 2011). Among the available geomagnetic indices, these three indices have been chosen for describing the $L_{\mathrm{PP}}$ as a function of geomagnetic activity because their variations can be physically interpreted and related to the specific magnetospheric current system (e.g., the ring current and polar electrojet). In this context, the widely used Kp index is difficult to interpret. However, it is related to the Ap index, which is more convenient to use since it is based on a linear scale.

The solar wind data were obtained from the Solar Wind Electron Proton and Alpha Monitor (SWEPAM; McComas et al., 1998) and the magnetometer (MAG; Smith et al., 1998) on board the Advanced Composition Explorer (ACE; Stone et al., 1998). We used the merged hour-averaged level-2 ACE data given at http://www.srl.caltech.edu/ACE/ASC/level2/.

We note that different coupling functions between the solar wind and the magnetosphere have been investigated by many authors (e.g., Gonzalez et al., 1994, and references therein). Their relative importance has often been revised (e.g., Newell et al., 2007).

For the correlation study we analyzed the following $L_{\mathrm{PP}}$ indicators based on the solar wind basic and derived parameters $B_{z}, \mathrm{BV}$ and $\mathrm{d} \Phi_{\mathrm{mp}} / \mathrm{d} t$ (Newell et al., 2007), defined as

$\mathrm{d} \Phi_{\mathrm{mp}} / \mathrm{d} t=V^{4 / 3} B_{T}^{2 / 3} \sin ^{8 / 3}\left(\theta_{c} / 2\right)$,

where $B_{T}=\sqrt{B_{y}^{2}+B_{z}^{2}}$ is the projection of IMF vector in the $Y-Z$ plane and $\theta_{c}=\arctan \left(B_{y} / B_{z}\right)$ is the IMF clock angle in GSM.

These coupling functions have been chosen because their role in changing the state of the magnetosphere may be physically interpreted. The conditions or processes that represent each of these functions are as follows. The energy transfer from the solar wind into the magnetosphere is most favorable when the IMF has a strong $B_{z}$ component oriented southward. Then a reconnection with the Earth's magnetic field becomes possible, and consequently the strength of convection increases, leading to the modification of the plasmapause position. The BV quantity is directly related to the interplanetary electric field and thus to the changes in the plasmapause shape and position. Studies by Verbanac et al. (2013) have shown that the magnetosphere responds in different manners to different solar drivers, e.g., coronal mass ejections and corotating interaction regions. They further show that the same BV range plays an equally important role for both types of magnetospheric drivers. Since in the present study we do not aim to make the distinction between the solar drivers of geomagnetic disturbances, we chose the BV quantity as the representative coupling function. Verbanac et al. (2013) also found that $\mathrm{BV}$ is strongly correlated with geomagnetic indices Ap, AE and Dst, so we expected this quantity to be a good measure for the response of the plasmapause as well.

The quantity $\mathrm{d} \Phi_{\mathrm{mp}} / \mathrm{d} t$ combines different physical processes responsible for the magnetospheric activity, such as the rate at which IMF field lines are convected toward the magnetopause, the fraction of field lines impacting the magnetosphere that merge, the amount of the opened flux, the length of the merging line. Newell et al. (2007) showed that among 20 employed coupling functions, $\mathrm{d} \Phi_{\mathrm{mp}} / \mathrm{d} t$ represents the interaction between the solar wind and magnetosphere best for a wide variety of geomagnetic activity, even better than $\mathrm{BsV}$ ( $\mathrm{Bs}$ is zero for $B_{z}>0$ ) which is one of the most widely used coupling function, and thus is used in the present study.

The analyzed $L_{\mathrm{PP}}$ are determined from data provided by the WHISPER instrument on board the Cluster satellites. The Cluster mission consists of four identical spacecraft (C1, C2, C3, and C4) launched in 2000 on similar elliptical polar orbits with a time period of $57 \mathrm{~h}$. The initial perigee was about $4 R_{\mathrm{E}}$ and the apogee at 19.6 $R_{\mathrm{E}}$ (Escoubet et al., 2001). Each satellite crosses the inner magnetosphere from the Southern to the Northern Hemisphere around the perigee. Due to the annual precession of the orbit, all MLTs are covered over the course of a year. Each spacecraft carries 11 instruments. The WHISPER data allow determining the electron density inside and outside the plasmasphere (Décréau et al., 2001; Darrouzet et al., 2009b; Lointier et al., 2013). The frequency spectra obtained during the passive and active (sounding) operation modes of the instrument carry out a direct or indirect determination of the electron plasma frequency $F_{\mathrm{P}}$. The electron density $N_{\mathrm{e}}$ is deduced from $F_{\mathrm{P}}$ by the relation $N_{\mathrm{e}}$ $\left(\mathrm{cm}^{-3}\right)=F_{\mathrm{P}}^{2}(\mathrm{kHz}) / 81$. The instrument can estimate electron densities up to $80 \mathrm{~cm}^{-3}$ due to the instrument frequency upper limit at $80 \mathrm{kHz}$, with a temporal resolution of $2 \mathrm{~s}$ on average. The uncertainty on the plasma frequency measurements is $163 \mathrm{~Hz}$, which gives a relative error on electron density of the order of $0.5-5 \%$ at densities higher than $20 \mathrm{~cm}^{-3}$ (Darrouzet et al., 2013).

Before 2007, the plasmapause was sometimes never encountered by Cluster, as the perigee was located around $4 R_{\mathrm{E}}$ (i.e., sometimes at higher radial distances than the plasma- 


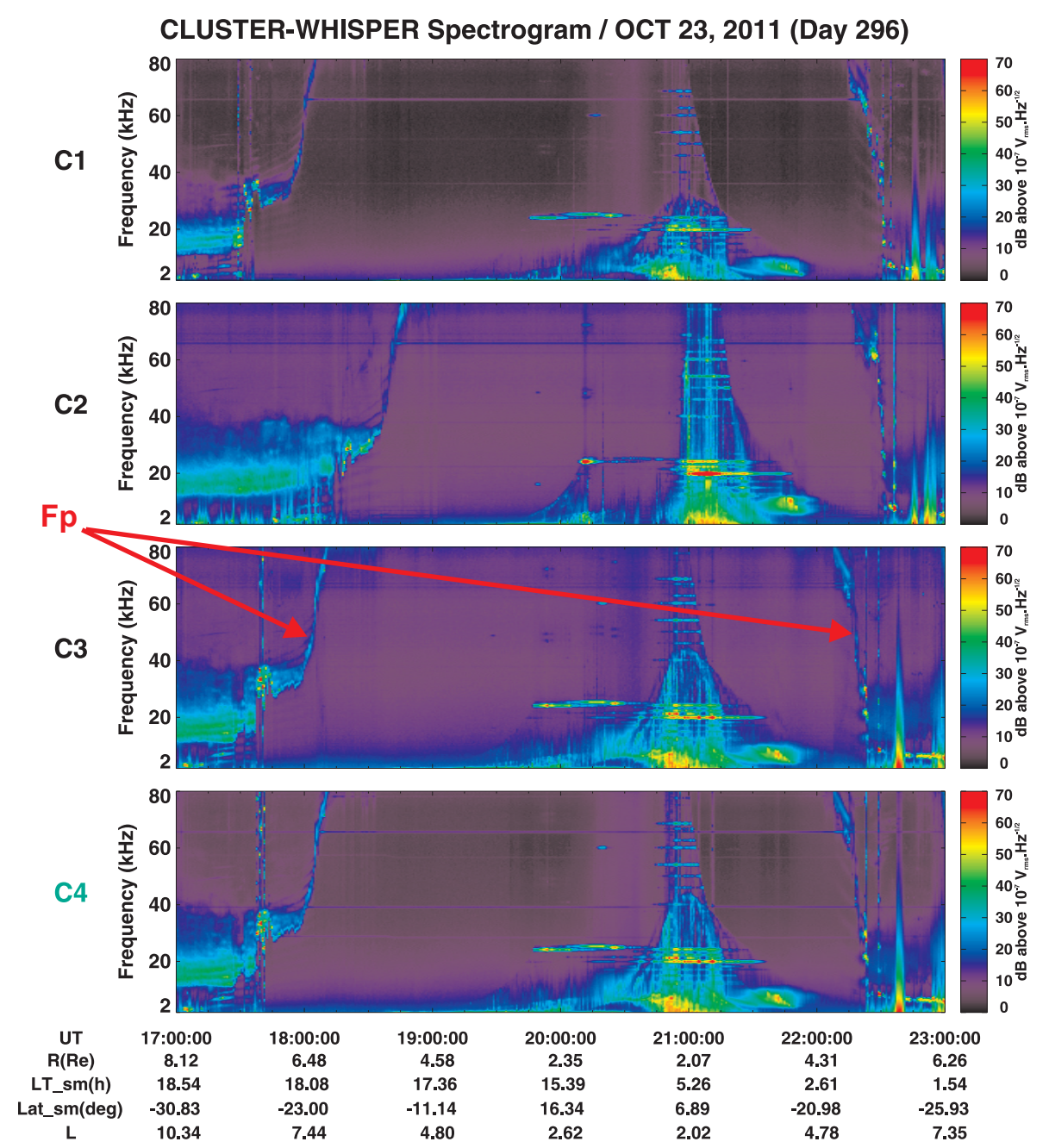

Figure 1. Time-frequency electric field spectrograms measured by the instrument WHISPER on board the four Cluster spacecraft on 23 October 2011, between 17:00 and 23:00 UT. The plasmapause position corresponds to the sharp increase in the electron plasma frequency $F_{\mathrm{P}}$ (visible as the clear blue line, indicated by the red arrows for $\mathrm{C} 3$ ), directly related to the electron density. The orbital parameters shown below the figure correspond to $\mathrm{C} 4$.

pause). During the investigated time period (2007-2011), the satellites orbit with the perigee located inside the plasmasphere, as close as $2 R_{\mathrm{E}}$, allowed us to determine the electron density inside and outside the plasmasphere from WHISPER (Darrouzet et al., 2013). We have used two different and complementary data sets of plasmapause positions determined from WHISPER data, during two different time periods and two different orbitographies. The first data set (April 2007 to March 2009) was determined by Darrouzet et al. (2013). During this time period, we have only used the $L_{\mathrm{PP}}$ determined from $\mathrm{C} 3$ because all three instruments needed in this first study were functioning well only on board this satellite. We have considered only the inbound crossings because the inbound and outbound ones were separated by only a few UT hours and a limited MLT difference (see, for instance, Figs. 1 and 3 of Lointier et al., 2013). We have further supplemented this sample by a second data set of plasmapause positions between July 2010 and December 2011 in order to have data from a time period with higher geomagnetic activity. During this time period, the inbound and outbound crossings were widely separated in both UT and MLT, so we were able to use both crossings. Note that we used all satellites available during this second time period if the data were available. The $L$ values were extracted from the CLWeb software (http://clweb.cesr.fr) using the IGRF2000 model for the internal magnetic field (IAGA, 2000) and the Tsyganenko T89 model for the external magnetic field (Tsyganenko, 1989). To determine the $L_{\mathrm{PP}}$, we follow Darrouzet et al. (2013), and we searched for the sharp increase in the electron plasma frequency, looking for a density increase of at least a factor of 3 over an $L$ distance of $0.5 R_{\mathrm{E}}$ or less with an increase up to a density larger than $20 \mathrm{~cm}^{-3}$. The location of the upper value 
of the density ramp is considered the position of the plasmapause. Note that the upper limit of the instrument is indeed low and induces limitations in our plasmapause determination technique. However, we have excluded from our statistical study the events with small-density gradients and small maximum electron density values (see the typical strong density gradient of our events on Fig. 1). Then we consider that the events selected here give an innermost plasmapause position, not far from the plasmapause position that would be defined as the middle of the plasmasphere boundary layer. Note that in this way, we have the same plasmapause position definition as in the study of Li et al. (2006). The presence of plasmaspheric plumes (Darrouzet et al., 2006, 2008) were further taken into account. We simply looked for the plasmapause and checked the presence of a plume. If there was one, we took care to not use the inner boundary of the plume as the plasmapause. In Fig. 1 we show an example of timefrequency electric field spectrograms measured by WHISPER on board the four Cluster satellites $(\mathrm{C} 1, \mathrm{C} 2, \mathrm{C} 3$, and C4) on 23 October 2011, between 17:00 and 23:00 UT. The plasmapause corresponds to the sharp increase in the electron plasma frequency, as seen for instance around 18:00 UT during the $\mathrm{C} 1, \mathrm{C} 3$ and $\mathrm{C} 4$ inbound plasmapause crossing and around 18:30 UT for C2 (see, respectively, the panels 1, 3, 4 and 2 of Fig. 1).

The relationships between the $L_{\mathrm{PP}}$ and both the solarwind- and Earth-based $L_{\mathrm{PP}}$ indicators are then investigated for three different MLT sectors (Sector1 - night sector (01:00-07:00 MLT); Sector2 - day sector (07:0016:00 MLT); Sector3 - evening sector (16:00-01:00 MLT)) and for all MLT taken together (details and results of the analyses are presented in Sect. 4). Sector1, Sector2 and Sector3 contain 67, 64 and 180 plasmapause crossings, respectively. Such MLT intervals were selected to ensure, as much as possible, adequate statistics in each time bin. The crosscorrelation analysis is applied and the delay times of the plasmapause to $L_{\mathrm{PP}}$ indicators are obtained. The time series to correlate are created as follows.

One series contains the determined $L_{\mathrm{PP}}$ which refers to the specific times (e.g., 7 April 2007, 19:49:48 UT). The second time series (of the same length as $L_{\mathrm{PP}}$ ) consists of given $L_{\mathrm{PP}}$ indicator values taken at a fixed time lag $\Delta t$ with respect to $L_{\mathrm{PP}}$. A correlation coefficient is computed between these two time series and then the procedure is repeated for time lags ranging between 0 and $30 \mathrm{~h}$, with a step of $1 \mathrm{~h}$ (data resolution). The hour (UT) at which the plasmapause crossing begins (e.g., 19:00:00 UT for the plasmapause crossing on 7 April 2007 at 19:49:48 UT) is taken as the time for the first value of the second time series.

A given $X-Y$ correlation corresponds to the linear form $Y(t)=a X\left(t^{*}\right)+b$, where $X\left(t^{*}\right)$ represents the value of $X$ that occurred $\Delta t$ hours before the true value of $Y(t)$. Thus $t^{*}$ is the "retarded time" $\left(t^{*}=t-\Delta t\right)$. Negative lag between two quantities, e.g., $\mathrm{BV}$ and $L_{\mathrm{PP}}$, hereinafter denoted as the $\mathrm{BV}-L_{\mathrm{PP}}$ correlation, means that $\mathrm{BV}$ is delayed with respect
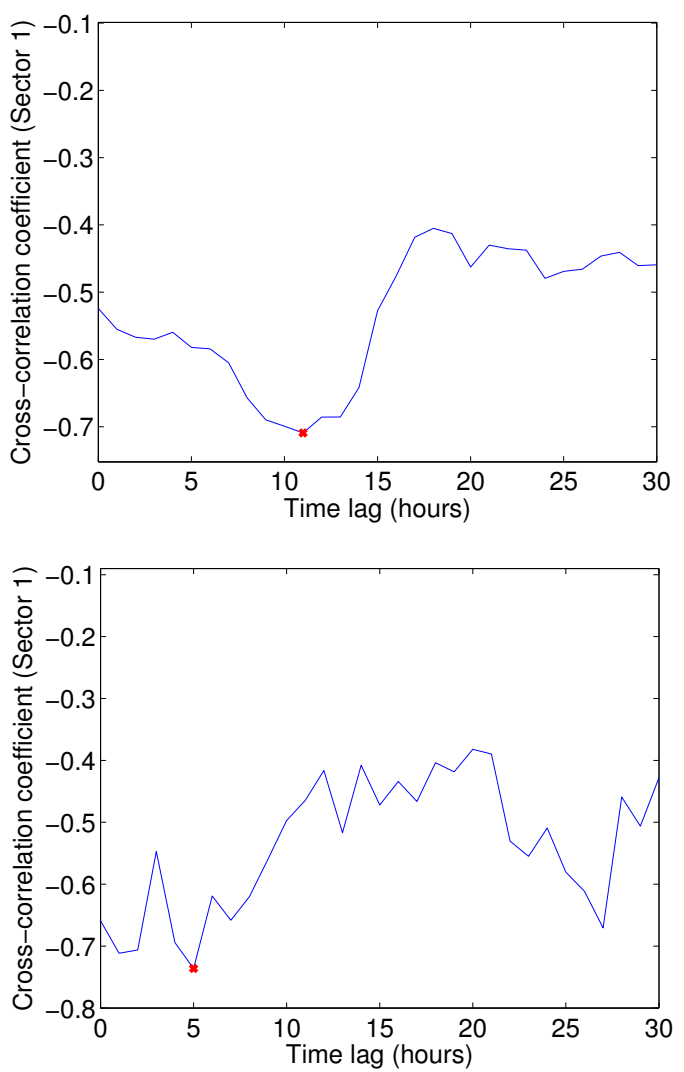

Figure 2. Cross-correlation function describing the BV- $L_{\mathrm{PP}}$ (top) and $\mathrm{AE}-L_{\mathrm{PP}}$ (bottom) relationships for MLT Sector1 (01:0007:00 MLT). The red cross indicates the highest-correlationcoefficient time lag.

Table 1. Total number of plasmapause positions and the minimum and maximum plasmapause position observed during different periods of solar activity: low phase (2007-2009) and increasing phase (2010-2011) of the solar cycle 23.

\begin{tabular}{lrrr}
\hline Period & $\begin{array}{r}\text { Total number } \\
\text { of positions }\end{array}$ & $L_{\min }\left(R_{\mathrm{E}}\right)$ & $L_{\max }\left(R_{\mathrm{E}}\right)$ \\
\hline $2007-2009$ & 80 & 3.7 & 8.8 \\
$2010-2011$ & 231 & 2.9 & 7.6 \\
\hline All years & 311 & 2.9 & 8.8 \\
\hline
\end{tabular}

to $L_{\mathrm{PP}}$. Such lags are not considered since they are not physical. Note that the zero time lag actually means any delay between 0 and $1 \mathrm{~h}$. Further note that using an upstream monitor ACE, the obtained time lags related to the solar-windbased $L_{\mathrm{PP}}$ indicators contain the response of the magnetosphere plus the propagation time (the time that the solar wind propagates between ACE position and the nose of the magnetosphere, which is $\sim 1 \mathrm{~h}$ on average).

In a preliminary analysis we tested the various lengths of the time interval prior to the Cluster plasmapause crossings. 
Table 2. Characteristics of the analyzed data set. The minimum or the maximum is taken over the interval of $30 \mathrm{~h}$ prior to the plasmapause crossing. Two values given for $B_{z}$ refer to southward and northward $B_{z}$ orientation $\left(B_{z}<0\right.$ and $\left.B_{z}>0\right)$.

\begin{tabular}{lrrrrrrr}
\hline & $\begin{array}{r}\mathrm{BV} \\
\left(\mathrm{mV} \mathrm{m}^{-1}\right)\end{array}$ & $\begin{array}{r}V \\
\left(\mathrm{~km} \mathrm{~s}^{-1}\right)\end{array}$ & $\begin{array}{r}B \\
(\mathrm{nT})\end{array}$ & $\begin{array}{r}B_{z} \\
(\mathrm{nT})\end{array}$ & $\begin{array}{r}\text { Dst } \\
(\mathrm{nT})\end{array}$ & $\begin{array}{r}\mathrm{Ap} \\
(\mathrm{nT})\end{array}$ & $\begin{array}{r}\mathrm{AE} \\
(\mathrm{nT})\end{array}$ \\
\hline all $L_{\mathrm{PP} \text { values }}$ & 11.1 & 680 & 24.5 & $-16.5,21.6$ & -132 & 154 & 1287 \\
$L_{\mathrm{PP}=2.9 R_{\mathrm{E}}}$ & 4.7 & 650 & 8 & $-3.8,3$ & -40 & 40 & 950 \\
$L_{\mathrm{PP}=8.8} R_{\mathrm{E}}$ & 1.5 & 310 & 3.5 & $-2,2.3$ & -10 & 4 & 130 \\
\hline
\end{tabular}

Table 3. The cross-correlation coefficients $R$ and the corresponding time lags $\Delta t$ (in hours) of the relationship between $L_{\mathrm{PP}}$ and $L_{\mathrm{PP}}$ indicators $\left(B_{z}, \mathrm{BV}, \mathrm{d} \Phi_{\mathrm{mp}} / \mathrm{d} t\right.$, Dst, Ap, AE) for the highest-correlation time lags. Negative $R$ denotes anticorrelation between $L_{\mathrm{PP}}$ indicators and $L_{\mathrm{PP}}$. The last four columns are the rms errors $(\sigma)$ of the best $L_{\mathrm{PP}}$ fits. Subscripts " $i$ " and "all" refer to the MLT Sectors1-3 (Sec1: 01:00-07:00 MLT; Sec2: 07:00-16:00 MLT; Sec3: 16:00-01:00 MLT) and to all MLT sectors, respectively.

\begin{tabular}{lrrrrrrrrrrrr}
\hline & $R_{1}$ & $\Delta t$ & $R_{2}$ & $\Delta t$ & $R_{3}$ & $\Delta t$ & $R_{\text {all }}$ & $\Delta t$ & $\sigma_{1}$ & $\sigma_{2}$ & $\sigma_{3}$ & $\sigma_{\text {all }}$ \\
\hline$B_{z}-L_{\mathrm{pp}}$ & 0.54 & 2 & 0.39 & 14 & 0.36 & 23 & 0.31 & 23 & 0.74 & 1.18 & 0.85 & 0.96 \\
$\mathrm{BV}-L_{\mathrm{pp}}$ & -0.71 & 11 & -0.66 & 15 & -0.57 & 27 & -0.53 & 27 & 0.62 & 0.96 & 0.73 & 0.86 \\
$\mathrm{~d} \Phi_{\mathrm{mp}} / \mathrm{d} t-L_{\mathrm{pp}}$ & -0.65 & 2 & -0.63 & 14 & -0.55 & 20 & -0.46 & 23 & 0.68 & 0.99 & 0.72 & 0.88 \\
\hline $\mathrm{Dst}-L_{\mathrm{pp}}$ & 0.71 & 0 & 0.73 & 7 & 0.64 & 14 & 0.57 & 7 & 0.62 & 0.87 & 0.70 & 0.83 \\
$\mathrm{Ap}-L_{\mathrm{pp}}$ & -0.69 & 5 & -0.64 & 11 & -0.59 & 21 & -0.53 & 10 & 0.63 & 0.98 & 0.74 & 0.85 \\
$\mathrm{AE}-L_{\mathrm{pp}}$ & -0.74 & 5 & -0.6 & 12 & -0.6 & 20 & -0.53 & 20 & 0.59 & 1.03 & 0.72 & 0.86 \\
\hline
\end{tabular}

The $24 \mathrm{~h}$ time range was first examined and then an additional, significant peak in the cross-correlation functions of all quantities around $\Delta t=27 \mathrm{~h}$ was identified. Accordingly the time interval has been enlarged. The highest correlation coefficient in each of the MLT sectors and also when all MLT are binned together is always found at a time lag of less than $30 \mathrm{~h}$, and thus we took the length of $30 \mathrm{~h}$ as optimal. This investigation of the most appropriate time interval prior to the plasmapause crossing indicates that it likely takes several hours for any change in the $L_{\mathrm{PP}}$ to propagate around the Earth for MLT sectors other than the postmidnight one (see also Lemaire and Pierrard, 2008). As an example in Fig. 2, we present the cross-correlation function between BV and $L_{\mathrm{PP}}$ and $\mathrm{AE}$ and $L_{\mathrm{PP}}$ in MLT Sector1. An increase in indicator value (here $\mathrm{BV}$ or $\mathrm{AE}$ ) will cause shrinking of the plasmapause (a decrease in $L_{\mathrm{PP}}$ ), which means that the correlation is negative. The highest-correlation-coefficient time lag $(\Delta t=11$ and $\Delta t=5 \mathrm{~h})$ is indicated in the figures with red cross. Note the appearance of the secondary peak at $\Delta t=27 \mathrm{~h}$ in the bottom panel of Fig. 2.

\section{Characteristics of the analyzed samples}

In addition to showing the minimum and maximum plasmapause extension, Table 1 contains the number of determined $L_{\mathrm{PP}}$ for the two solar activity periods: the low (2007-2009) and the increasing phase (2010-2011).

To determine the $L_{\mathrm{PP}}$, we processed the data collected by Cluster. Sometimes there are no data because the instrument is off, the satellite is off or because there are eclipses. Some- times, the plasmapause is crossed at too high density so that its position cannot be clearly identified. This results in the unequal data distribution through considered years. Note that most of the determined $L_{\mathrm{PP}}$ come from measurements obtained in 2011 . The $L_{\mathrm{PP}}$ ranges between 2.9 and $8.8 R_{\mathrm{E}}$. The mean $L_{\mathrm{PP}}$ obtained by averaging all 311 determined $L_{\mathrm{PP}}$ values amounts to $5.6 R_{\mathrm{E}}$. Except for 2011, the considered time span includes declining, minimum and early increasing phases of the solar cycle. During this period (2007-2010) the geomagnetic activity was mostly low, and consequently the plasmapause was located quite far from the Earth (on average at $7.9 R_{\mathrm{E}}$ ). As the solar activity starts to increase in 2011 , we observed that the plasmapause shrinks to as low as $2.9 R_{\mathrm{E}}$.

To give an overview of the characteristics of the analyzed samples, we present in Table 2 the maximal values of $1 \mathrm{AU}$ solar wind parameters (basic and derived) studied and geomagnetic indices related to the $L_{\mathrm{PP}}$ closest to the Earth $\left(2.9 R_{\mathrm{E}}\right), L_{\mathrm{PP}}$ furthest from the Earth $\left(8.8 R_{\mathrm{E}}\right)$ and to all considered $L_{\mathrm{PP}}$ values. Maxima are taken over the interval of $30 \mathrm{~h}$ prior to the plasmapause crossing. For all parameters maxima are considerably different for low and high solar activity periods. The two values given for $B_{z}$ refer to southward and northward $B_{z}$ orientation $\left(B_{z}<0\right.$ and $\left.B_{z}>0\right)$.

The lowest plasmapause that occurred in 2011 is not associated with the largest solar wind parameters and also not with the largest geomagnetic indices found within the used data sets. Note that according to the highest amplitude Dst $($ Dst $=-40 \mathrm{nT})$, geomagnetic activity was weak (Sugiura and Chapman, 1960; Gonzalez et al., 1994). However, maximal $\mathrm{AE}$ was significant $(\mathrm{AE}=950 \mathrm{nT})$, being even larger 


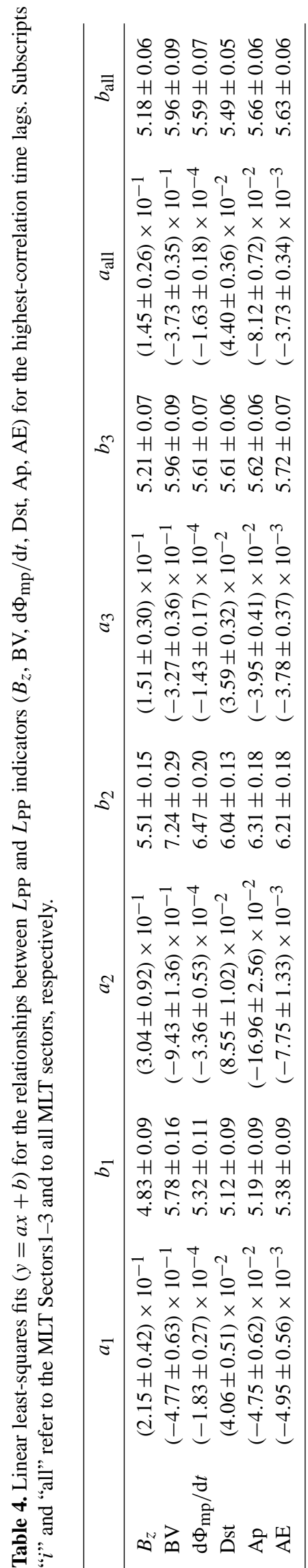

than the highest $\mathrm{AE}$ associated with the high-speed solar wind streams driving geomagnetic activity during solar cycle 23 as reported by Verbanac et al. (2013). It may indicate that in this case, the auroral electrojet played a more important role than the ring current in the formation of the plasmapause. The largest $L_{\mathrm{PP}}$, which occurred in 2008, is preceded by much lower maximal values of both solar wind parameters and geomagnetic indices.

The maximal values of all $L_{\mathrm{PP}}$ indicators are found for $L_{\mathrm{PP}}=3.9 R_{\mathrm{E}}$ and thus not for the lowest $L_{\mathrm{PP}}$ within our sample. This confirms that the individual peak values of the plasmapause indicators may not be the most appropriate measure to characterize the plasmapause position.

\section{Results}

In the following we relate the $L_{\mathrm{PP}}$ indicators to the determined $L_{\mathrm{PP}}$ by applying the cross-correlation analysis. We follow the method explained in Sect. 2. Most of the analyzed data distributions indicate that two (or even three, e.g., for AE) linear least-square relationships should be adopted, one for lower and the other for higher values of the $L_{\mathrm{PP}}$ indicators. Since the period studied includes mostly periods of quiet solar activity, our data sets contain only few points at higher $L_{\mathrm{PP}}$ indicator values which is certainly not enough to perform a reliable regression. Thus, the linear relationships are obtained by taking all $L_{\mathrm{PP}}$ values within each of the three sectors and also when all MLT are binned together.

In Table 3 we present the linear least-squares correlation coefficients $R$, the time lags $\Delta t$ obtained for each of the three considered MLT sectors and all MLT taken together, and the rms errors (RMSEs) of the best fits. Note that positively defined $L_{\mathrm{PP}}$ indicators $\left(\mathrm{BV}, \mathrm{d} \Phi_{\mathrm{mp}} / \mathrm{d} t, \mathrm{Ap}, \mathrm{AE}\right)$ are anticorrelated (negative $R$ ) with $L_{\mathrm{PP}}$, and thus their increase causes shrinking of the plasmapause. On the other hand, negatively defined $L_{\mathrm{PP}}$ indicators $\left(B_{z}\right.$ and Dst) are correlated (positive $R)$ with $L_{\mathrm{PP}}$. The correlations are evidently the highest in Sector 1 and drop through Sector 2 to Sector3. The only exception is Dst, where the correlation coefficient is somewhat higher in Sector2 than in Sector1. Between the considered solar-wind-based $L_{\mathrm{PP}}$ indicators, $\mathrm{BV}$ is the best correlated with $L_{\mathrm{PP}}$ in all sectors, and also when all MLT are binned together. The smallest differences among sectors, as quantified by $R$, are found for $\mathrm{d} \Phi_{\mathrm{mp}} / \mathrm{d} t$. Concerning geomagnetic indices, the highest correlation is $\mathrm{AE}-L_{\mathrm{PP}}$ in Sector1, and Dst $-L_{\mathrm{PP}}$ in both Sector 2 and Sector3. Note the significant decrease in $\mathrm{AE}-L_{\mathrm{PP}}$ correlation coefficients from Sector1 to Sector2. When all MLTs are binned together, correlation coefficients for the $\mathrm{AE}-L_{\mathrm{PP}}$ and $\mathrm{Ap}-L_{\mathrm{PP}}$ are the same and lower than the correlation coefficient for Dst $-L_{\mathrm{PP}}$ relationship. The obtained time lags increase from Sector1 to Sector3, for all $L_{\mathrm{PP}}$ indicators. For $B_{z}$ and $\mathrm{d} \Phi_{\mathrm{mp}} / \mathrm{d} t$ time lags are identical, except in Sector3. The time lag for $\mathrm{BV}-L_{\mathrm{PP}}$ is exceptional in Sector1, being the largest $\Delta t$ found in this sec- 

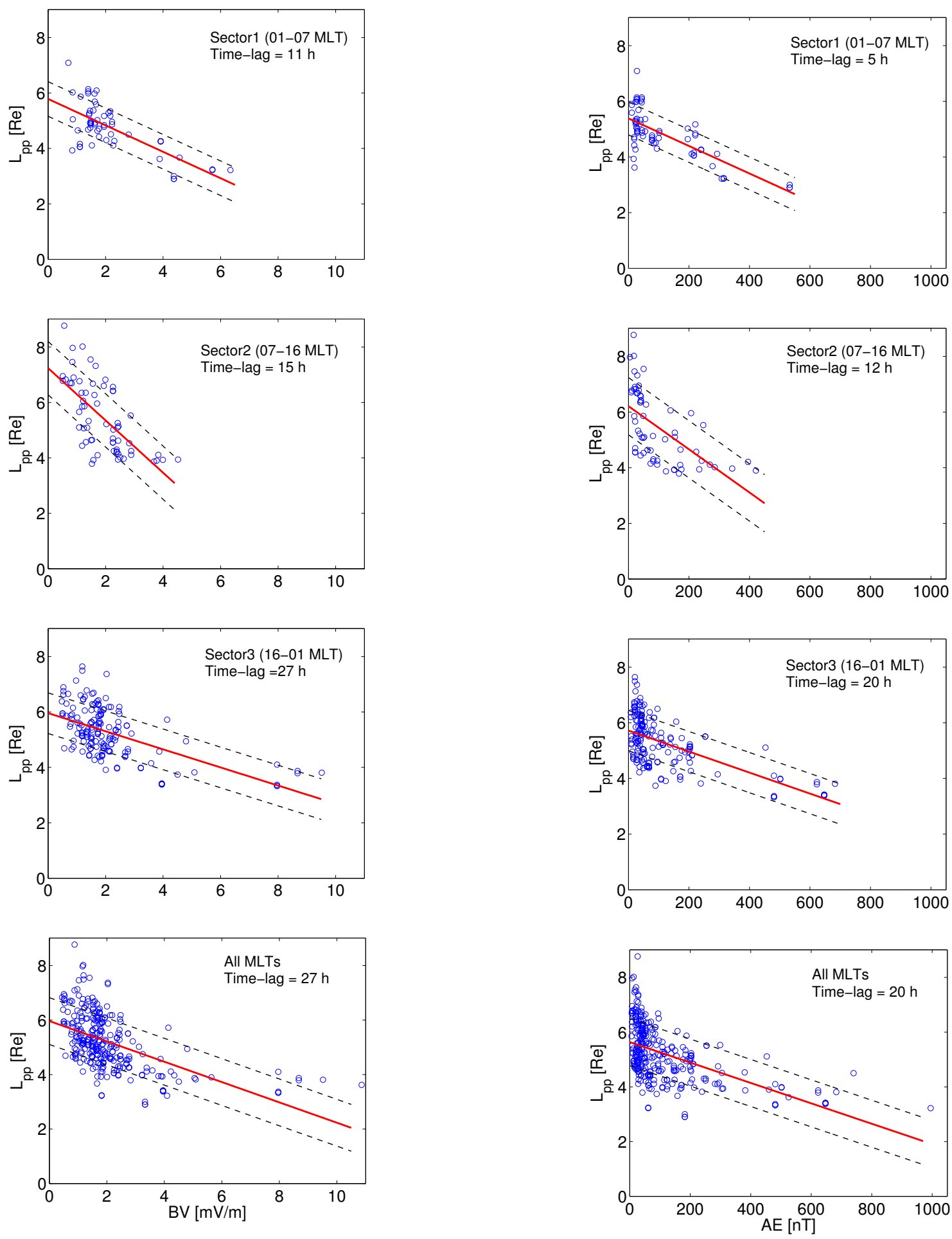

Figure 3. The $L_{\mathrm{pp}}\left(R_{\mathrm{E}}\right)$ as a function of $\mathrm{BV}\left(\mathrm{mV} \mathrm{m}^{-1}\right)$ for three different MLT Sectors (Sector1 (01:00-07:00 MLT); Sector2 (07:0016:00 MLT); Sector3 (16:00-01:00 MLT)) and for all MLTs binned together (from top to bottom). Red lines represent the linear fits for the highest-correlation time lag. Dashed lines represent the residual standard deviation.

Figure 4. The $L_{\mathrm{pp}}\left(R_{\mathrm{E}}\right)$ as a function of $\mathrm{AE}(\mathrm{nT})$ for three different MLT Sectors1-3 (01:00-07:00, 07:00-16:00, 16:00-01:00 MLT) and for all MLTs (from top to bottom). Red lines represent the linear fits for the highest-correlation time lag. Dashed lines represent the residual standard deviation. 
tor. Similar $\Delta t$ are obtained for Ap and AE in all three sectors. Notably shorter $\Delta t$ are obtained for Dst (4-7 h shorter depending on the sector). It is interesting to note that for almost all $L_{\mathrm{PP}}$ indicators, we found a second peak at a time lag of around $27 \mathrm{~h}$ (see Fig. 2, bottom). This additional peak found at larger $\Delta t$ probably causes the large $\Delta t$ values when all MLT are considered together. This should be investigated in a further study. The RMSEs are approximately $0.6-1.2 R_{\mathrm{E}}$ in all sectors. For all indicators the RMSEs are the largest in Sector2. For solar wind parameters, the largest and the lowest RMSEs are found for $B_{z}$ and $\mathrm{BV}$, respectively, regardless of the sector. A large RMSE for $B_{z}-L_{\mathrm{PP}}$ most likely reflects the fact that a northward-oriented $B_{z}$ also plays an important part in eroding the plasmapause, at least at lower $B_{z}$ values. For instance, $L_{\mathrm{PP}}$ around $3.7 R_{\mathrm{E}}$ is observed at $B_{z}$ oriented northward. Note that these values are very similar to the lowest $L_{\mathrm{PP}}$ values found for southward $B_{z}$. Concerning geomagnetic indices, the lowest RMSE is obtained for AE in Sector1 and for Dst in both Sector2 and Sector3 and all MLTs.

Linear least-squares fit coefficients for the highestcorrelation time lag used to obtain the relationships between the $L_{\mathrm{PP}}$ and considered $L_{\mathrm{PP}}$ indicators are presented in Table 4 . For all $L_{\mathrm{PP}}$ dependencies the slopes are the steepest in Sector2. The ratio between the slope in Sector2 and that in Sector 1 or Sector3 is $\sim 4$ for Ap- $L_{\mathrm{PP}}$, while it is $\sim 2$ for the other $L_{\mathrm{PP}}$ indicators. However, note that the slopes in Sector3 are somewhat lower than the slopes in Sector1. Thus, the same change in the specific $L_{\mathrm{PP}}$ indicator will likely cause the largest movement of $L_{\mathrm{PP}}$ in Sector2 and the smallest in Sector3. According to parameter $b$ of the linear least-squares fits, for all investigated $L_{\mathrm{PP}}$ dependences, the smallest plasmapause extension is allowed in the night sector (Sector1) and its largest extension in the day sector (Sector2) due to the plume formation.

We show the BV- $L_{\mathrm{PP}}, \mathrm{AE}-L_{\mathrm{PP}}$ and Dst $-L_{\mathrm{PP}}$ scatterplots for the highest-correlation time lag in Figs. 3a-d, $4 a-d$ and $5 \mathrm{a}-\mathrm{d}$, respectively. The fitted linear relations (solid lines) clearly show a trend of decreasing $L_{\mathrm{PP}}$ with increasing $\mathrm{BV}$ and $\mathrm{AE}$ and increasing $L_{\mathrm{PP}}$ with decreasing Dst. However, all displayed data distributions show that $L_{\mathrm{PP}}$ only shrinks to a particular value as the $L_{\mathrm{PP}}$ indicator increases and then appears to saturate. Namely, there is no $L_{\mathrm{PP}}$ below $\sim 3,3.8$, 3.3 and $3 R_{\mathrm{E}}$ in Sectors $1-3$ and all MLT, respectively. Since the majority of our $L_{\mathrm{PP}}$ values are placed at lower values of the analyzed $L_{\mathrm{PP}}$ indicators, this must be taken only as an indication of the general plasmapause behavior.

The most probable $L_{\mathrm{PP}}$ values in each of the three sectors and for all MLT are determined using the calculated linear fits for all of the $L_{\mathrm{PP}}$ indicators. Table 5 contains the fitted $L_{\text {PP }}$ values for low and high activity. The indicator values at high activity are those at which $L_{\mathrm{PP}}$ comes closest to the Earth. This happens in Sector 2 for all $L_{\mathrm{PP}}$ dependencies, and we associate $L_{\mathrm{PP}} \sim 2.5 R_{\mathrm{E}}$ in Sector 2 with high activity.

Note that these indicator values for high activity, which cause significant shrinking of the plasmapause, are associ-
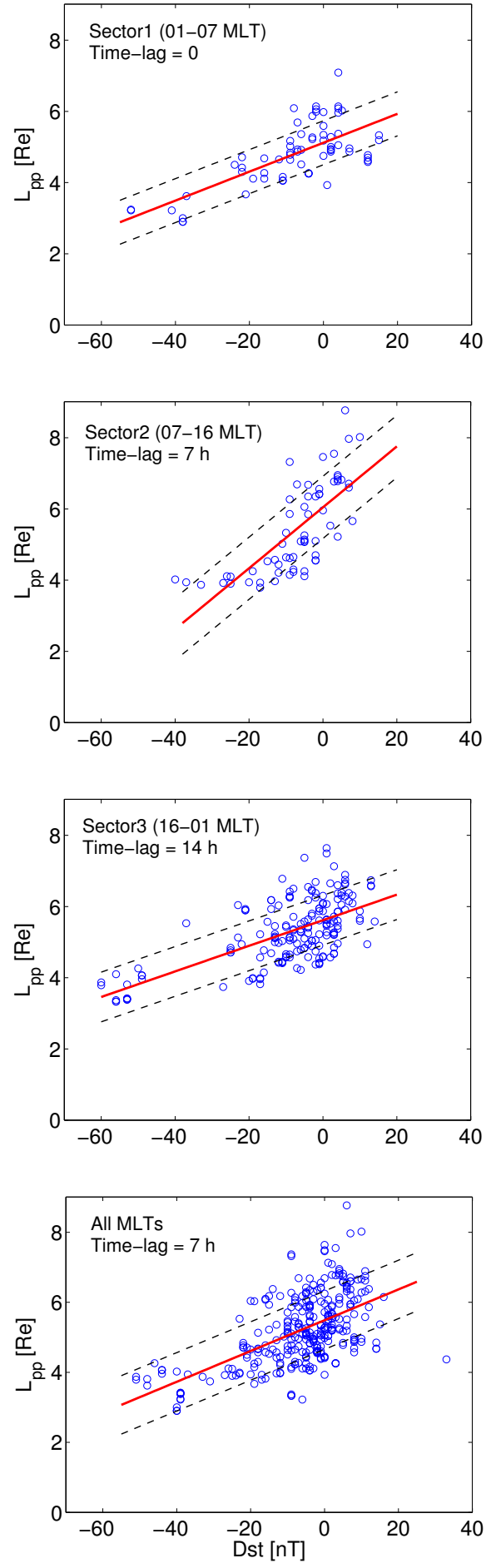

Figure 5. The $L_{\mathrm{pp}}\left(R_{\mathrm{E}}\right)$ as a function of Dst (nT) for three different MLT Sectors1-3 (01:00-07:00, 07:00-16:00, 16:00-01:00 MLT) and for all MLTs (from top to bottom). Red lines represent the linear fits for the highest-correlation time lag. Dashed lines represent the residual standard deviation. 
Table 5. The $L_{\mathrm{PP}}$ obtained from the linear least-square fits listed in the Table 4 for low and high activity. The indicator values at high activity are those at which $L_{\mathrm{PP}}$ amounts to $\sim 2.5 R_{\mathrm{E}}$ in Sector2. See text for details.

\begin{tabular}{ccc|cc|cc|cc|cc|cc}
\hline & \multicolumn{2}{c}{$B_{z}(\mathrm{nT})$} & \multicolumn{2}{c|}{$\mathrm{BV}\left(\mathrm{mV} \mathrm{m}^{-1}\right)$} & $\mathrm{d} \Phi_{\mathrm{mp}} / \mathrm{d} t\left(\mathrm{~km} \mathrm{~s}^{-1}\right)^{4 / 3}(\mathrm{nT})^{2 / 3}$ & Dst $(\mathrm{nT})$ & \multicolumn{2}{c|}{$\mathrm{Ap}(\mathrm{nT})$} & \multicolumn{2}{c}{$\mathrm{AE}(\mathrm{nT})$} \\
\cline { 2 - 12 } & -0.2 & -10 & 1 & 5 & $0.5 \times 10^{4}$ & $1.2 \times 10^{4}$ & -10 & -40 & 5 & 22 & 30 & 475 \\
\hline Sect1 & 4.78 & 2.68 & 5.30 & 3.40 & 4.41 & 3.13 & 4.71 & 3.50 & 4.95 & 4.15 & 5.24 & 3.04 \\
Sect2 & 5.45 & 2.47 & 6.30 & 2.52 & 4.80 & 2.45 & 5.19 & 2.62 & 5.47 & 2.58 & 5.98 & 2.53 \\
Sect3 & 5.17 & 3.70 & 5.63 & 4.32 & 4.89 & 3.90 & 5.26 & 4.18 & 5.42 & 4.75 & 5.61 & 3.93 \\
SeAll & 5.15 & 3.73 & 5.59 & 4.10 & 4.77 & 3.64 & 5.05 & 3.73 & 5.25 & 3.87 & 5.52 & 3.86 \\
\hline
\end{tabular}

ated with the stronger values of $L_{\mathrm{PP}}$ indicators although they are of moderate intensity, as seen in Table 5 (e.g., Dst $=$ $-40 \mathrm{nT}$ ). The reason is that our analysis is based on the $L_{\mathrm{PP}}$ indicator value at the highest-correlation time lag instead of the interval maxima, as noted before.

Taking into account the RMSE given in Table 3, information about $L_{\mathrm{PP}}$ reported in Table 5 shows that at low activity, the plasmapause is located closest to the Earth in Sector1 and furthest away from it in Sector2. At higher activity the closest plasmapause is found in Sector2 and the furthest away in Sector3. These results reveal the MLT asymmetries at both low and higher activity levels. During low activity, day-night asymmetry is more prominent (with the bulge on the dayside). As activity increases, the bulge is displaced toward the evening, and day-evening asymmetry becomes more prominent. Interestingly, all the $L_{\mathrm{PP}}$ indicators used provide us with the same conclusion.

\section{Conclusions}

The cross-correlation analysis was applied to study the plasmapause position $L_{\mathrm{PP}}$, determined using the WHISPER instrument on board the Cluster satellites, as a function of various solar wind and Earth-based $L_{\mathrm{PP}}$ indicators. The maximum (in an absolute sense) value of the $L_{\mathrm{PP}}$ indicators that precedes the plasmapause crossing is generally higher for smaller $L_{\mathrm{PP}}$ than for larger $L_{\mathrm{PP}}$. However, our analyses show that the value at the highest-correlation time lag is more appropriate for describing the plasmapause responses to any disturbances rather than the maximum values in the prevailing interval before the $L_{\mathrm{PP}}$, as commonly used in other studies (e.g., Moldwin et al., 2002; O'Brien and Moldwin, 2003, and references therein). Thus, the obtained results (fit parameters) cannot be directly compared, but general findings confirm those of previous research (Carpenter and Anderson, 1992; Moldwin et al., 2002; O'Brien and Moldwin, 2003; Heilig and Lühr, 2013). All studies show that the plasmapause is closer to Earth during geomagnetically active periods, with the plasmapause bulge displaced toward dusk.

Delay times of the $L_{\mathrm{PP}}$ in relation to the arrival of $L_{\mathrm{PP}}$ indicators were obtained. The values range from 0 to $27 \mathrm{~h}$, depending on the MLT sectors and on the $L_{\mathrm{PP}}$ indicators.
The analysis is performed for three different MLT sectors (Sector1 - night (01:00-07:00 MLT); Sector2 - day (07:0016:00 MLT); Sector3 - evening (16:00-01:00 MLT)) and for all MLT taken together. Based on the correlation coefficients and RMSE, we conclude that all $L_{\mathrm{PP}}$ indicators studied are capable of describing the observed plasmapause position well. Among solar wind coupling functions, BV is found to be a slightly superior $L_{\mathrm{PP}}$ indicator in all sectors and for all MLT binned together. As regards geomagnetic indicators, $\mathrm{AE}$ is found to be the best one in Sector 1 and Dst is the best in Sector2, Sector3, as well as for all MLT. O'Brien and Moldwin (2003) also found that AE is particularly effective in the night and dawn sectors. However, no MLT dependence is visible in their Dst model.

Among all indicators, $B_{z}$ provides the least reliable $L_{\mathrm{PP}}$. Generally, the correlations are the highest in Sector1 and decrease through Sector2 to Sector3. Our $B_{z}-L_{\mathrm{PP}}$ correlation for all MLTs is somewhat lower than the one obtained by Larsen et al. (2007) and the time lag is very different. The discrepancy may result from different methodology and different plasmapause observations used in both studies.

The obtained time lags increase from Sector1 to Sector3, for all $L_{\mathrm{PP}}$ indicators. The time lag for $\mathrm{BV}-L_{\mathrm{PP}}$ is exceptional in Sector 1 and amounts to $11 \mathrm{~h}$. Similar delays are obtained for Ap and AE in all three sectors. Notably shorter time delays (4-7 h shorter depending on the sector) are obtained for Dst, suggesting that the ring current may play an important role in quickly peeling off the plasmapause via non-convection processes.

Since the highest correlation coefficients and the fastest plasmapause response to different $L_{\mathrm{PP}}$ indicators are in Sector1, the following simple scenario may be involved. The information about the history (e.g., strength and variability) of any of the $L_{\mathrm{PP}}$ indicators during $30 \mathrm{~h}$ previous to the $L_{\mathrm{PP}}$ changes is stored in the plasmasphere. After approximately $2-5 \mathrm{~h}$ (note again that $\mathrm{BV}$ is an exception), the plasmasphere responds and begins to erode on the nightside. Due to the Earth's rotation, the information is passed to the dayside and later to the evening sector. According to all indicators studied, it takes about $24 \mathrm{~h}$ for any change to propagate all around the Earth. This may suggest that there is some instability that likely propagates around the Earth, which is consistent with the mechanism of interchange instability pro- 
posed by Lemaire and Pierrard (2008). Our analysis further indicates that this instability propagates with a velocity that may slightly differ from the corotation velocity.

The scatter around the fit of the plasmapause is larger for lowest values of $L_{\mathrm{PP}}$ indicators as noted also by Moldwin et al. (2002). This is the most prominent in Sector2. According to our findings, $L_{\mathrm{PP}}$ exhibits the largest values on the dayside (somewhere between 07:00 and 16:00 MLT) and smallest values in the postmidnight sector during low activity levels. This is in agreement with Gringauz and Bezrukikh (1976). By contrast, Moldwin et al. (2002) noted a slight asymmetry in the noon-midnight direction, with an $L_{\mathrm{PP}}$ peak in the night sector. During more active periods, we observed that $L_{\mathrm{PP}}$ peaks in the evening sector (between 16:00 and 01:00 MLT) and the smallest plasmapause expansions are found on the dayside (between 07:00 and 16:00 MLT). This is in agreement with results presented by O'Brien and Moldwin (2003) and Heilig and Lühr (2013), while this asymmetry was not found in any other studies (e.g., Gringauz and Bezrukikh, 1976; Carpenter and Anderson, 1992; Moldwin et al., 2002). Further, at enhanced magnetic activity, we observed a tendency for $L_{\mathrm{PP}}$ to saturate as there is no $L_{\mathrm{PP}}$ below a certain value (depending on the MLT sector). However, at high $L_{\mathrm{PP}}$ indicator values, we do not have sufficient data points to make a general conclusion.

We plan to continue this study by enlarging our $L_{\mathrm{PP}}$ data set, possibly during a period of higher solar activity. This will allow us to verify the obtained results and to more reliably constrain the lower limit of $L_{\mathrm{PP}}$ for various MLT sectors. Further, the possibility to perform the analyses looking at narrow MLT sectors will enable us to more precisely identify both the MLT in which the plasmapause is formed and the displacement of the bulge during the active magnetic period. With the extension of our study, we hope to get a better insight into the physical mechanisms responsible for the plasmapause formation. This is very important since the plasmapause plays a crucial role in the propagation of the mass and energy distribution within the inner magnetosphere.

Acknowledgements. The results presented in this paper are based on data from Cluster and ACE satellites and from the Kyoto World Data Center for geomagnetism. We thank all the staff involved for providing high-quality data. The presented work was initiated during G. Verbanac's visit to the Belgian Institute for Space Aeronomy, which was supported by the European Union Seventh Framework Programme (FP7/2007-2013) - COMESEP. G. Verbanac is especially thankful to N. Crosby (Project Coordinator and Team Leader of the COMESEP project) and B. Vrsnak (Croatian COMESEP Team Leader) and to J. De Keyser. V. Pierrard thanks the STCE (Solar-Terrestrial Centre of Excellence) and the Belgian Federal Science Policy (Belspo) regarding the Interuniversity Attraction Pole program, project P7/08 CHARM. V. Pierrard and F. Darrouzet thank Belspo for the Cluster Prodex project (contract 13127/98/NL/VJ). All authors thank ESA for the Cluster mission.
We gratefully acknowledge constructive suggestions from the two reviewers.

The topical editor G. Balasis thanks B. Heilig and M. Vellante for help in evaluating this paper.

\section{References}

Brice, N. M.: Bulk Motion of the Magnetosphere, J. Geophys. Res., 72, 5193-5211, 1967.

Carpenter, D. L. and Anderson, R. R.: An ISEE/whistler model of equatorial electron density in the magnetosphere, J. Geophys. Res., 97, 1097-1108, doi:10.1029/91JA01548, 1992.

Carpenter, D. L. and Lemaire, J.: The Plasmasphere Boundary Layer, Ann. Geophys., 22, 4291-4298, doi:10.5194/angeo-224291-2004, 2004.

Chappell, C. R., Harris, K. K., and Sharp, G. W.: A study of the influence of magnetic activity on the location of the plasmapause as measured by OGO 5, J. Geophys. Res., 75, 50-56, doi:10.1029/JA075i001p00050, 1970a.

Chappell, C. R., Harris, K. K., and Sharp, G. W.: The reaction of the plasmapause to varying magnetic activity, in: Particles and Fields in the Magnetosphere, edited by: McCormac, B. M., Astrophysics and Space Science Library, 17, 148-153, doi:10.1007/978-94-010-3284-1, 1970b.

Darrouzet, F. and De Keyser, J.: The dynamics of the plasmasphere: Recent results, J. Atmos. Sol. Ter. Phys., 99, 53-60, doi:10.1016/j.jastp.2012.07.004, 2013.

Darrouzet, F., De Keyser, J., Décréau, P. M. E., Gallagher, D. L., Pierrard, V., Lemaire, J. F., Sandel, B. R., Dandouras, I., Matsui, H., Dunlop, M., Cabrera, J., Masson, A., Canu, P., Trotignon, J. G., Rauch, J. L., and André, M.: Analysis of plasmaspheric plumes: CLUSTER and IMAGE observations, Ann. Geophys., 24, 1737-1758, doi:10.5194/angeo-24-1737-2006, 2006.

Darrouzet, F., De Keyser, J., Décréau, P. M. E., El LemdaniMazouz, F., and Vallières, X.: Statistical analysis of plasmaspheric plumes with Cluster/WHISPER observations, Ann. Geophys., 26, 2403-2417, doi:10.5194/angeo-26-2403-2008, 2008.

Darrouzet, F., De Keyser, J., and Pierrard, V. (Eds.): The Earth's Plasmasphere: A Cluster and IMAGE Perspective, Springer, New York, USA, 296 pp., 2009a.

Darrouzet, F., Pierrard, V., Benck, S., Lointier, G., Cabrera, J., Borremans, K., Yu Ganushkina, N., and De Keyser, J.: Links between the plasmapause and the radiation belt boundaries as observed by the instruments CIS, RAPID, and WHISPER onboard Cluster, J. Geophys. Res., 118, 4176-4188, doi:10.1002/jgra.50239, 2013.

Darrouzet, F., Gallagher, D. L., André, N., Carpenter, D. L., Dandouras, I., Décréau, P. M. E., De Keyser, J., Denton, R. E., Foster, J. C., Goldstein, J., Moldwin, M. B., Reinisch, B. W., Sandel, B. R., and Tu, J.: Plasmaspheric density structures and dynamics: Properties observed by the Cluster and IMAGE missions, Space Sci. Rev., 145, 55-106, doi:10.1007/s11214-008-9438-9, 2009b.

Décréau, P. M. E., Fergeau, P., Krannosels'kikh, V., Lévêque, M., Martin, Ph., Randriamboarison, O., Sené, F. X., Trotignon, J. G., Canu, P., and Mögensen, P. B.: WHISPER, a resonance sounder and wave analyser: Performances and perspectives for the Cluster mission, Space Sci. Rev, 79, 157-193, doi:10.1023/A:1004931326404, 1997. 
Décréau, P. M. E., Fergeau, P., Krasnoselskikh, V., Le Guirriec, E., Lévêque, M., Martin, Ph., Randriamboarison, O., Rauch, J. L., Sené, F. X., Séran, H. C., Trotignon, J. G., Canu, P., Cornilleau, N., de Féraudy, H., Alleyne, H., Yearby, K., Mögensen, P. B., Gustafsson, G., André, M., Gurnett, D. C., Darrouzet, F., Lemaire, J., Harvey, C. C., Travnicek, P., and Whisper experimenters (Table 1): Early results from the Whisper instrument on Cluster: an overview, Ann. Geophys., 19, 1241-1258, doi:10.5194/angeo-19-1241-2001, 2001.

Escoubet, C. P., Fehringer, M., and Goldstein, M.: Introduction, The Cluster mission, Ann. Geophys., 19, 1197-1200, doi:10.5194/angeo-19-1197-2001, 2001.

Gallagher, D., Craven, P. D., and Comfort, R. H.: Global core plasma model, J. Geophys. Res., 105, 18819-18833, doi:10.1029/1999JA000241, 2000.

Goldstein, J., Wolf, R. A., Sandel, B. R., and Reiff, P. H.: Electric fields deduced from plasmapause motion in IMAGE EUV images, Geophys. Res. Lett., 31, L01801, doi:10.1029/2003GL018797, 2004.

Gonzalez, W. D., Joselyn, J. A., Kamide, Y., Kroehl, H. W., Rostoker, G., Tsurutani, B. T., and Vasyliunas, V. M.: What is a geomagnetic storms, J. Geophys. Res., 99, 5771-5792, doi:10.1029/93JA02867, 1994.

Gringauz, K. I. and Bezrukikh, V. V.: Asymmetry of the Earth's plasmasphere in the direction noon-midnight from Prognoz and Prognoz 2 data, J. Atmos. Terr. Phys., 38, 1071-1076, 1976.

Heilig, B. and Lühr, H.: New plasmapause model derived from CHAMP field-aligned current signatures, Ann. Geophys., 31, 529-539, doi:10.5194/angeo-31-529-2013, 2013.

Horwitz, J. L., Menteer, S., Turnley, J., Burch, J. L., Winningham, J. D., Chappell, C. R., Craven, J. D., Frank, L. A., and Slater, D. W.: Plasma boundaries in the inner magnetosphere, J. Geophys. Res., 91, 8861-8882, doi:10.1029/JA091iA08p08861, 1986.

IAGA: International Association of Geomagnetism and Aeronomy (IAGA) Division V, Working Group 8: International Geomagnetic Reference Field 2000, Geophys. J. Int., 141, 259-262, doi:10.1046/j.1365-246x.2000.00121.x, 2000.

Larsen, B. A., Klumpar, D. M., and Gurgiolo, C.: Correlation between plasmapause position and solar wind parameter, J. Atmosph. Sol. Terr. Phys., 69, 334-340, doi:10.1016/jastp.2006.06.017, 2007.

Lemaire, J. and Pierrard, V.: Comparison between two theoretical mechanisms for the formation of the plasmapause and relevant observations, Geomagnetism and Aeronomy, 48, 553-570, doi:10.1134/S0016793208050010, 2008.

Lemaire, J. F. and Gringauz, K. I.: The Earth's Plasmasphere, Cambridge University Press, New York, USA, 372 pp., 1998.

Li, X., Baker, D. N., O’Brien, T. P., Xie, L., and Zong, Q. G.: Correlation between the inner edge of outer radiation belt electrons and the innermost plasmapause location, Geophys. Res. Lett., 33, L14107, doi:10.1029/2006GL026294, 2006.

Lointier, G., Darrouzet, F., Décréau, P. M. E., Vallières, X., Kougblénou, S., Trotignon, J. G., and Rauch, J.-L.: Refilling process in the plasmasphere: a 3-D statistical characterization based on Cluster density observations, Ann. Geophys., 31, 217-237, doi:10.5194/angeo-31-217-2013, 2013.

McComas, D. J., Bame, S. J., Barker, P., Feldman, W. C., Phillips, J. L., Riley, P., and Griffee, J. W.: Solar Wind
Electron Proton Alpha Monitor (SWEPAM) for the Advanced Composition Explorer, Space Sci. Rev., 86, 563-612, doi:10.1023/A:1005040232597, 1998.

McIlwain, C. E.: A Kp dependent equatorial electric field model, Adv. Space Res., 6, 187-197, doi:10.1016/0273-1177(86)903315, 1986.

Moldwin, M. B., Downward, L., Rassoul, H. K., Amin, R., and Anderson, R. R.: A new model of the location of the plasmapause: CRRES results, J. Geophys. Res., 107, 1339, doi:10.1029/2001JA009211, 2002.

Newell, P. T., Sotirelis, T., Liou, K., Meng, C.-I., and Rich, F. J.: A nearly universal solar wind-magnetosphere coupling function inferred from 10 magnetospheric state variables, J. Geophys. Res., 112, A01216, doi:10.1029/2006JA012015, 2007.

O'Brien, T. P. and Moldwin, M. B.: Empirical plasmapause models from magnetic indices, Geophys. Res. Lett., 30, 1152, doi:10.1029/2002GL016007, 2003.

Pedatella, N. M. and Larson, K. M.: Routine determination of the plasmapause based on COSMIC GPS total electron content observations of the midlatitude trough, J. Geophys. Res., 115, A09301, doi:10.1029/2010JA015265, 2010.

Pierrard, V. and Lemaire, J.: Development of shoulders and plumes in the frame of the interchange instability mechanism for plasmapause formation, Geophys. Res. Lett., 31, L05809, doi:10.1029/2003GL018919, 2004.

Pierrard, V. and Stegen, K.: A three-dimensional dynamic kinetic model of the plasmasphere, J. Geophys. Res., 113, A10209, doi:10.1029/2008JA013060, 2008.

Pierrard, V. and Voiculescu, M.: The 3D model of the plasmasphere coupled to the ionosphere, Geophys. Res. Lett., 38, L12104, doi:10.1029/2011GL047767, 2011.

Pierrard, V., Khazanov, G. V., Cabrera, J., and Lemaire, J.: Influence of the convection electric field models on predicted plasmapause positions during magnetic storms, J. Geophys. Res., 113, A08212, doi:10.1029/2007JA012612, 2008.

Prölss, G.: Physics of the Earth's Space Environment, SpringerVerlag Berlin Heidelberg, Germany, 251 pp., 2004a.

Prölss, G.: Physics of the Earth's Space Environment, SpringerVerlag Berlin Heidelberg, Germany, 406-415, 2004b.

Smith, C. W., L’Heureux, J., Ness, N. F., Acuña, M. H., Burlaga, L. F., and Scheifele, J.: The ACE Magnetic Fields Experiment, Space Sci. Rev., 86, 613-632, doi:10.1023/A:1005092216668, 1998.

Stone, E., Frandsen, A., Mewaldt, R., Christian, E., Margolies, D., Ormes, J., and Snow, F.: The Advanced Composition Explorer, Space Sci. Rev., 86, 1-22, doi:10.1023/A:1005082526237, 1998.

Sugiura, M. and Chapman, S.: The average morphology of geomagnetic storms with sudden commencement, Abhandl. Akad. Wiss. Goettingen Math. Physik. Kl 4, 53 pp., 1960.

Tsyganenko, N.: A magnetospheric magnetic field model with a warped tail current sheet, Planet. Space Sci., 37, 5-20, doi:10.1016/0032-0633(89)90066-4, 1989.

Verbanac, G., Vršnak, B., Temmer, M., Mandea, M., and Korte, M.: Four decades of geomagnetic and solar activity: 1960-2001, J. Atmos. Sol. Terr. Phys., 72, 607-616, doi:10.1016/j.jastp.2010.02.017, 2010.

Verbanac, G., Vršnak, B., Temmer, M., and Veronig, A.: Equatorial coronal holes, solar wind high-speed streams, and 
their geoeffectiveness, Astron. Astrophys., 526, A20-1-A20-14, doi:10.1051/0004-6361/201014617, 2011.

Verbanac, G., Živković, S., Vršnak, B., Bandić, M., and Hojsak, T.: Comparison of geoeffectiveness of coronal mass ejections and corotating interaction regions, Astron. Astrophys., 558, 10 pp., doi:10.1051/0004-6361/201220417, 2013. 